\title{
ASPECTOS MODERNOS DE LA REPARACIÓN POR DAÑO MORAL: CONTRASTE ENTRE EL DERECHO CHILENO Y EL DERECHO COMPARADO'
}

\author{
Carmen Domínguez Hidalgo \\ Doctora en Derecho \\ Profesora de Derecho Civil \\ Pontificia Universidad Católica de Chile \\ Universidad de Concepción
}

\section{1) CONSIDERACIONES GENERALES}

No es una afirmación poco frecuente la de que el Derecho civil es una disciplina estática, en la que nada resta por aportar ni desarrollar, pues los siglos de estudio que se le han dedicado, agotaron su repertorio de temas. No obstante, una simple observación de las revistas de Derecho, libros y publicaciones jurídicas de los más diversos paises, de las sentencias que se emiten en materias civiles, del sinnúmero de leyes que se promulgan y proyectos de ley que se proponen, permiten responder a la afirmación reseñada y entender que ella sólo puede provenir de un profundo desconocimiento del Derecho civil actual.

Las transformaciones que esta rama del Derecho ha sufrido a lo largo de su historia son tantas y tan variadas que intentar reseñarlas implicaría abordar un trabajo de largos años. Baste, para fundamentar esta aseveración, con aludir, por ejemplo, al Derecho de Familia y las numerosas reformas que tanto en los derechos codificados como en los consuetudinarios le han afectado, sustituyendo casi todos los principios básicos en que se asentaba (por ejemplo, el de protección a la familia legítima) para constatar que, por el contrario, esta es una rama jurídica en constante y progresiva evolución. Así lo confirman, por otro lado, todos los nuevos enfoques que, desde perspectivas sociológicas, económicas y filosóficas se han efectuado y se efectúan del Derecho civil generando profundas polémicas tal como, por no citar sino un caso, todo el debate que ha desencadenado el análisis económico del Derecho, que han realizado los partidarios del Ilamado Movimiento "Laws and Economics" como Calabresi o Posner.

1 Esta conferencia consigna parte de las investigaciones realizadas con ocasión tanto de nuestra tesis doctoral titulada "El daño moral derivado de contrato", defendida en la Universidad Complutense de Madrid en julio de 1995 como de los estudios realizados en el marco de un proyecto de investigación financiado por la Dirección de Investigación de la Universidad de Concepción y por Fondecyt (proyecto 1970070-97). 
Si existe una materia que en el Derecho comparado ha sido objeto de cambios y que ha experimentado un sorprendente desarrollo en los últimos años es la de la responsabilidad civil, como lo atestiguan tanto la multiplicación de demandas resarcitorias como el aumento creciente de los montos indemnizatorios, tendencias ostensibles en todos los países industrializados e incluso en algunos en vías de desarrollo, como es el caso notable de Argentina. La evolución ha sido tan sorprendente y radical que son numerosos los autores ${ }^{2}$ que se han preguntado si no se estará en el presente ante una verdadera crisis de la responsabilidad pues tanto su fundamento como su objeto o finalidad son sumamente discutibles.

Lo cierto es que, más allá de las discusiones teóricas, la explicación del protagonismo alcanzado por la responsabilidad civil se encuentra en que ha pasado a ser uno de los mecanismos más expeditos y eficientes de tutela de la persona en términos que, tomando las palabras del jurista español LOPEZ JACOISTE ${ }^{3}$, constituye una garantía genérica de "plenitud personal".

Es una garantía genérica pues, como lo ha destacado claramente una sentencia del Tribunal Supremo español "a diferencia de acciones de otra naturaleza, la acción de resarcimiento de daños por culpa extracontractual se fundamenta en la cualidad del perjudicado, sin requerir título de dominio, bastando la cualidad de accionante como perjudicado por el acto ilícito en cuestión, para que el resarcimiento se imponga por tratarse de intereses jurídicamente protegidos que no han de ser necesariamente los basados en el derecho de dominio"14. En efecto, si bien existen acciones defensivas destinadas a proteger aspectos específicos de la persona, sólo la acción de responsabilidad concede esa protección genérica de la persona que sólo nace y se justifica por su condición de perjudicado en el sentido de que, siguiendo a GARCIA ENTERRIA, la sola existencia del perjuicio injusto hace nacer el derecho subjetivo consistente en recabar la reparación, y que no se identifica necesariamente con el derecho o el interés que fue objeto de menoscabo.

$Y$ es que, desde que la persona en sí misma, su dignidad, ha pasado a ser el objeto de preocupación esencial del Derecho, proclamado incluso constitucionalmente por todos los textos modernos vigentes en el Occidente, en términos tales que ha sido considerado como el "valor-síntesis", por ejemplo, en España, todo el resto del ordenamiento juridico ha debido y debe leerse desde ese prisma. En otras palabras, adquirida esa conciencia en la sociedad y proclamada ella en nuestras normas jurídicas más importantes, toda la interpretación del resto del Derecho que le está jerárquicamente subordinado debe ser orientada por esos valores ${ }^{5}$.

2 En tal sentido, vid. TUNC, La responsabilité civile, Paris, 1981, pág. 6; VINEY, Introduction a la responsabilité civile, en Traité de Droit civil de Ghestin, Paris, 1995, págs. 56 y ss.

LOPEZ JACOISTE, Transformaciones y paradojas de la responsabilidad extracontractual. Discurso leido el 10 de enero de 1994 en su recepción pública como académico de número de la Real Academia de Jurisprudencia y Legislación. Madrid, 1994.

4 Sentencia Tribunal Supremo de España de 10 de noviembre de 1980.

5 Sobre la llamada interpretación desde la Constitución, vid. PERALTA. La interpretación del ordenamiento juridico conforme a la norma fundamental del Estado, Madrid, 1994. 
Ahora bien, si ello no se ha efectuado en los países más avanzados en la materia formalmente o directamente sino desde hace unos años dentro de lo que se conoce como el fenómeno de la "constitucionalización del Derecho civil", esa revisión del Derecho en general ha generado, indirectamente, desde fines del siglo pasado, una transformación del Derecho de las obligaciones y de los contratos y, específicamente, de la responsabilidad civil. Es así como se han visto transformados su fundamento clásico, su estructura y, en lo que nos interesa hoy, en uno de sus elementos como lo es la existencia de perjuicio.

Las revisiones introducidas a los principios básicos que gobernaban el daño en la doctrina clásica han significado, en primer término, una alteración del rol que le era tradicionalmente asignado. En este sentido, el daño ha dejado de ser un mero elemento o requisito para la procedencia de la acción de responsabilidad civil para pasar a constituir su verdadero fundamento. En efecto, el acento de la moderna responsabilidad se halla colocado no en la reprochabilidad de la conducta realizada por el responsable como antaño sino en la defensa de la víctima a la que se quiere dejar indemne de cualquier perjuicio que se le haya inferido; el fundamento de la reparación pareciere estar entonces más bien en el daño y no en la culpa ${ }^{6}$. A juzgar por la tendencia jurisprudencial y legislativa imperante, el requisito indispensable para la procedencia de una reparación es la existencia de un daño causado a la víctima, en términos tales que pareciera que, una vez acreditado este elemento, todo el esfuerzo de los tribunales se concentra en elaborar un razonamiento lógico que permita, de acuerdo a las premisas del caso en cuestión, indemnizarlo?.

Pero además, la propia noción de daño se ha visto absolutamente alterada al haberse ampliado radicalmente. Así, de una idea estrictamente patrimonialista del perjuicio que concebía como tal exclusivamente a los daños de contenido económico se ha pasado a la plena certeza en cuanto a que también comprende a los perjuicios morales. Estos últimos exigen, en la concepción moderna, una respuesta tan firme y extensa como la que, desde siempre y especialmente a partir de la codificación de nuestros Derechos, se viene otorgando a los daños patrimoniales. Cierto es que este principio no ha sido recogido en todos los sistemas con igual fidelidad pero, al menos, parece existir una tendencia generalizada hacia su consagración legal o jurisprudencial. De aquí que, preguntarse sobre la procedencia de una respuesta jurídica a estos perjuicios, parezca inoficioso.

Desde luego, porque todos los obstáculos tradicionalmente esgrimidos en contra de su reparación han sido superados, al menos en materia extracontractual que no en la contractual según veremos.

Así, ningún sentido tiene discutir sobre la inmoralidad de una eventual reacción ante ellos. La idea antigua en la fórmula gráfica de MORANGE $^{8}$ según la cual era

6 Asi, lo resaltan, entre otros, ROUJOU DE BOUBEE, Essai sur la notion de réparation, th., Paris, 1974, págs. 69 y ss.; ALPA y BESSONE, La responsabilitá del produttore, Milano, 1980, pág. 127.

7 En idéntico sentido, YZQUIERDO TOLSADA, La responsabilidad civil contractual y extracontractual, vol.I, Madrid. 1993. pág, 19; DIEZ-PICAZO, La responsabilidad civil hoy, en Anuario de Derecho civil, 1972, pág. 732.

${ }^{8}$ MORANGE, A propos d'un revirement de jurisprudence... La réparation de la douleur morale par le Conseil d'Etat, en D.1962, chr., pág. 17 . 
"prácticamente indecente" conceder una reparación por este concepto pues sólo conduciría a cifrar en dinero, el dolor o sufrimiento o, más en general, aquellos bienes que por su valor para la persona no hay dinero que pueda reemplazarles, prácticamente escandaliza en la óptica actual pues es innegable que el perjudicado tiene derecho a alguna reacción por parte del Derecho ante este tipo de lesiones. Más aún, no tiene sentido sostener que el individuo tiene que soportar la carga de dolor que le corresponde cuando, de hecho, la tutela jurídica de su patrimonio es prácticamente absoluta. ¿Porqué proteger tan intensamente los bienes o intereses patrimoniales y abandonar la protección de todos esos otros bienes que no tienen contenido económico? Esa es una pregunta que, en el desarrollo actual del Derecho civil comparado, se responde por sí sola.

Tampoco admite mayor defensa la objeción clásica de que era "teóricamente imposible" una reparación del daño moral, al no caber, por un lado, ni la forma más perfecta de reparación -la específica- al tratarse de perjuicios imposibles de borrar ni, por otro, la reparación por equivalente desde que se traduce en el pago de una suma dineraria idéntica al valor perdido, traducción que deviene imposible cuando se trata de prestaciones o bienes que no tienen un contenido económico o material. En el presente podemos decir con seguridad que, por lo pronto, no cabe cuestionar la procedencia de la reparación específica sobre la que está conteste la casi totalidad de la doctrina, además que en algunas legislaciones ella es favorecida por sobre la entrega de una suma de dinero y, en otras, se hacen procedentes ciertas formas de esta reparación.

Por otra parte, las dificultades de reducción monetaria presentadas por este tipo de perjuicios no impiden su reparación. De partida porque la condena pecuniaria es tan sólo una de sus formas posibles. Pero además porque, tal como se ha admitido en sede aquiliana, debe entenderse que la entrega de una suma de dinero por este concepto no pretende ser un equivalente exacto del perjuicio causado, objetivo inalcanzable incluso ante los daños materiales, sino una compensación otorgada a la víctima a fin de que se procure el equivalente que ella juzgue oportuno: una compensación satisfactoria.

Por lo demás, en una argumentación que, por los límites de esta exposición no podemos transcribir, bien puede sostenerse y demostrarse que toda reparación ya sea en forma específica o por equivalente es siempre un sustituto, una "compensación", Siguiendo la gráfica expresión de HEBRAUD, la reparación es siempre compensatoria y lo que es satisfactorio es la entrega de una suma de dinero ${ }^{9}$.

\section{2) BREVE EVOLUCIÓN DE LA INDEMNIZACIÓN POR DAÑO MORAL EN EL DERECHO CHILENO.}

Si todas esas consideraciones generaron una larga polémica en sistemas como el francés o español, en la actualidad plenamente superadas, lo mismo puede afirmarse en nuestro Derecho. Primero, porque, por razones que ignoramos, ese debate nunca llegó aquí ni a nuestra doctrina ni a nuestra jurisprudencia la que, sin mayores fundamentaciones, abrió las puertas al resarcimiento del daño moral en la esfera extracontractual por el simple recurso a una reinterpretación gramatical del art. 2314 y 2329.

HEBRAUD, Prefacio a la obra de ROU JOU DE BOUBEE, op.cit., pág. 11. 
No se piense que esa fue una elaboración ciertamente original. Bien puede decirse que la admisibilidad de una reparación por daño moral en la esfera extracontractual se verá motivada en Chile por la evolución producida en el Derecho comparado, fundamentalmente en el Derecho francés. Incluso más, el razonamiento esgrimido por nuestra jurisprudencia para abrir las puertas a esa suerte de razonamiento será exactamente la misma que la invocada por las primeras decisiones y opiniones francesas. Así, el argumento clásico de que "los arts. 2314 y 2329 del Código civil ordenan indemnizar todo daño... Conforme a la doctrina, daño es todo menoscabo que experimente un individuo en su persona y bienes, la pérdida de un beneficio de indole material o moral, de orden patrimonial o extrapatrimonial' ${ }^{10}$ no es sino la recepción directa del razonamiento francés, anterior en el tiempo en más de 70 años $^{11}$, según el cual "el art. 1382 - equivalente a nuestro art.2314-, por lo general de sus términos, se aplica tanto al daño moral como al material' 12 .

En segundo término, la discusión teórica en cuanto a la procedencia de este rubro resarcitorio aparece inútil pues, en el presente, nadie la cuestiona. Antes bien, todo aquél que ejerce una acción de responsabilidad civil por la vía extracontractual, reclama una suma importante a título de daño moral que, luego de su revisión a través de las sucesivas instancias, normalmente sólo es reducida pero nunca denegada.

Sin embargo, pese a la certeza y claridad de tal evolución, numerosos son los vacíos y contradicciones que nuestro sistema presenta en esta materia, aún más evidentes si se le contrasta con el estado de la cuestión en aquellos paises que han alcanzado un notable desarrollo de la responsabilidad civil. El estado actual de la reparación por daño moral requiere de una adaptación urgente en algunas materias, so riesgo de constituirse, como observaremos a continuación, en una partida incierta y arbitraria, con todos los peligros que ello comporta.

No debe olvidarse que aquí nos enfrentamos frente a un tema de vital trascendencia: la dignidad de la persona. Todo el insuficiente desarrollo de la responsabilidad civil nos demuestra que nuestro sistema no ha adquirido conciencia en torno a esta cuestión. Y en especial, así sucede en materia de daño moral.

\section{3) LOS PRINCIPIOS QUE GOBIERNAN LA REPARACION DEL DAÑO MORAL EN CHILE. SU CONTRASTE CON EL DERECHO COMPARADO.}

\section{1) CONCEPTO Y CLASES DE DAÑOS}

El primer gran problema que se percibe en esta materia, es la propia noción de daño moral empleada y aceptada mayoritariamente un nuestro sistema. Así, en la idea

Corte Suprema, 3 de junio de 1973. Rev. de Der, y Juris,7, secc.4, pág. 75

11 En efecto, en Francia, la primera sentencia que acogió la indemnización del daño moral es de 15 de junio de 1833 (Cass. Chambres réunies, S.1833, 1, 458) ; en cambio, en Chile, es de 27 de julio de 1907 (Corte de Apelaciones de Santiago, Rev, de Der. y Juris., $t$. 4, secc. 2, pág. 149

12 En tal sentido, vid, por todas, Civ.13 de febrero 1923, D.P. 1923, I, pág. 52, nota LALOU. 
más difundida por nuestras sentencias y nuestra doctrina, a quienes debemos remitirnos pues no existe texto legal alguno que lo defina, esta especie de perjuicio consistiría en el "dolor, aflicción y angustia que naturalmente debe sufrir la víctima" ${ }^{13}$. "en el dolor, la aflicción, el pesar que causa en los sentimientos o afectos el hecho ilícito, ya sea en la víctima o en sus parientes más cercanos" ${ }^{14}$.

En otros términos, en la concepción habitualmente utilizada, el daño moral comprendería exclusivamente las secuelas psíquicas que el hecho ilícito le causa, esto es el conocido pretium doloris. Nuevamente, ello no tiene nada de original pues, en general, ha sido esa la noción inicialmente adoptada por los distintos sistemas al abrir paso a una reparación por este concepto.

No obstante, ella ha sido completamente abandonada pues, en la medida que se ha adquirido conciencia de qué es lo que constituye en esencia a la persona, resulta ser un concepto estricto, que entraba la utilización de esta forma de reparación como un medio adecuado y especialmente idóneo para la protección de la persona.

Así, deja fuera todos los atentados contra los denominados bienes, atributos o derechos de la personalidad (tales como honor, imagen, intimidad privada y familiar) que son de naturaleza extrapatrimonial y, por lo mismo, no pueden sino generar este tipo de reparación aunque no hayan importado secuelas psíquicas en el perjudicado. En otros términos, deja fuera de resarcimiento y, con ello, impide acceder a la víctima a una de las vías más expeditas de tutela a aquellos bienes o derechos que constituyen la condición misma de persona.

Tampoco permite incluir la indemnización de los menoscabos extrapatrimoniales ocasionados a las personas jurídicas, en la medida en que obviamente no pueden padecer dolor, cuando, si en verdad constituyen sujetos de Derecho, merecen igual defensa, claro está, en aquellos aspectos, bienes o derechos que, por su naturaleza, tienen o se les reconoce.

Por último, esta noción importa una confusión entre las consecuencias del daño y el daño en sí mismo. El dolor o el sufrimiento son las repercusiones que el atentado produce en el espíritu o en el cuerpo, pero no constituyen su esencia. Por el contrario, el perjuicio viene determinado por el menoscabo a ciertos derechos o intereses que el ordenamiento jurídico reconoce en toda persona, como lo demuestra la circunstancia de que, aún en presencia de padecimientos psíquicos, no existe un deber de reparación sino se demuestra que provienen del atentado a algún bien o interés. Así, tomando el ejemplo propuesto por el jurista argentino ZANNONI, si se presencia como un conductor atropella desaprensivamente a un peatón en plena vía pública, no se puede demandar ningún tipo de indemnización por más que se haya experimentado dolor por ese hecho si no se demuestra la titularidad de algún interés jurídico en la conservación de la vida de esa persona ${ }^{15}$. 
De aquí que, modernamente, se tenga un concepto muy amplio de daño moral que comprende todo lo que venimos de reseñar $y$, más en general, la lesión de cualquier derecho o interés extrapatrimonial de la persona. Incluso la propia nomenclatura de "daño moral" debe ser matizada porque, a diferencia de lo que acontece en Chile, la especie de perjuicios que se opone al daño material es el no patrimonial o extrapatrimonial, que comprende a su vez, una amplia gama de perjuicios.

Como hemos sostenido ${ }^{16}$, en realidad, la expresión empleada habitualmente en nuestro sistema para referirse a este perjuicio sólo se justifica en la medida que, de manera idéntica a lo que acontece con el daño material en virtud del art.1556 del CC. la entendamos como sinónima de una categoría en la que se incluyen todas las consecuencias no económicas del hecho ilícito 0 , en su caso, del incumplimiento de la obligación patrimonial.

Sólo es en esa perspectiva en la que esta forma de reparación podrá prestar efectiva utilidad, comprendiendo todas las facetas y secuelas que el atentado a la persona genera, tal como sucede actualmente en el Common Law y, entre los sistemas que pertenecen a nuestra misma tradición, en el Derecho francés.

Allí, desde la decisión que en 1833 admitiera por primera vez la indemnización a este título, la jurisprudencia ha realizado un perfeccionamiento constante de esta poderosa herramienta. Uno de ellos ha sido la progresiva precisión de las distintas especies de perjuicios morales o extrapatrimoniales que pueden ser reclamados y tales como: a) pérdida de agrado (préjudice d'agrément), partida con la que persigue indemnizar, siguiendo a VINEY, "la pérdida de los goces ordinarios de la vida cualquiera sea su naturaleza y origen es decir al conjunto de sentimientos, molestias y frustraciones resentidas en todos los aspectos de la existencia cotidiana en razón de la lesión y sus secuelas" 17 y $\tan$ variadas como, por ejemplo, usar de una habilidad que se poseía (tocar un instrumento musical) o una facultad que se tenía (caminar y con ello pasear por el borde del mar); b) perjuicio estético (préjudice esthétique) consistente en las mutilaciones, deformaciones o, en general, en los daños a la estética del perjudicado que le perturban la vida normal en cuanto generan discriminación objetiva o subjetiva. Tiene especial gravedad cuando afecta a una persona joven (pretium juventatis); c) pretium doloris que, a diferencia de lo que sucede en Chile, comprende exclusivamente los sufrimientos físicos experimentados por la víctima; d) perjuicio de afecto (préjudice d'affection) con el que se persigue indemnizar tanto el daño directamente infligido a una persona, por ejemplo, por la pérdida o destrucción de una cosa a la que se encontraba afectivamente vinculado como la aflicción que causa a ciertas personas la lesión o muerte de la víctima, por existir esa misma vinculación; e) perjuicio sexual (préjudice sexuel) referido a la imposibilidad moral que tiene la víctima para llevar una vida sexual normal como consecuencia del atentado. Incluso comprende la pérdida de esa vida sexual derivada de la pérdida de deseo de su cónyuge a causa de la invalidez que ésta sufre; f) perjuicio juvenil (préjudice juvénile) que corresponde al dolor particular que

Sobre el punto, véase nuestro trabajo, titulado "La indemnización por daño moral. Modernas tendencias en el Derecho civil chileno y comparado", Revista Chilena de Derecho, vol. 25, n², págs. 27 y ss., en especial págs. 41 y ss.

17 VINEY. Traité de Droit civil (dir. Jacques Ghestin), vol.V (Les obligations. La responsabilité: effets), Paris, 1988, pág 196. 
experimenta una persona al joven al comprobar su propia desgracia y la pérdida de toda posibilidad de llevar una vida futura normal; g) perjuicio derivado de la contaminación de virus del SIDA después de transfusión sanguínea y que consiste en el temor ante la muerte que experimenta el enfermo SIDA en una enfermedad todavía incurable 0 , en el caso del seropositivo, en el temor que su estado de salud se agrave ${ }^{18}$. Abarca además la discriminación y rechazo social que supone la contaminación con este virus.

Como puede observarse, ellas abarcan una gama muy amplia de secuelas no económicas que en Chile no está siendo cubiertas en su totalidad o que, por el contrario, se están sobreevaluando. En tal sentido, como se insistirá más adelante, la precisión de estas distintas especies de perjuicios permite, por una parte, indemnizar todo el daño no patrimonial efectivamente causado y, por otro, evitar la arbitrariedad implícita en una evaluación genérica por daño moral.

Además, revela una sensibilidad jurídica de los órganos judiciales y del ordenamiento jurídico frente a la realidad del perjuicio, digna de elogio, más aún cuando ella está siendo objeto de una revisión constante, de manera a mantener la vigencia y utilidad de este aspecto de la responsabilidad civil.

\section{2) PRUEBA Y EVALUACION}

No existe en nuestra jurisprudencia ninguna exigencia en la acreditación del daño moral ni una fundamentación de su evaluación desde que, por una antigua doctrina jurisprudencial, la apreciación y evaluación de esta especie de perjuicio son cuestiones que caen dentro de la discrecionalidad judicial de los jueces de fondo ${ }^{19}$. Por lo mismo es imposible saber en nuestro pais con exactitud cuando existe daño moral o no ni porqué se le cifra en tal o cual suma. El resultado es, como es fácil imaginar, falta absoluta de uniformidad en las decisiones y arbitrariedad con los consiguientes peligros de injusticia e inseguridad que ello acarrea.

Cierto es que esa doctrina es reconocida por doquier desde que, por su propia naturaleza, el daño moral resiste a una acreditación semejante a la de los daños materiales o una evaluación exacta. En España, por ejemplo, se ha resuelto reiteradamente que "la determinación del quantum indemnizatorio no es revisable en casación pues se trata de una cuestión de hecho entregada a los tribunales de instancia" 20 . Del mismo modo, en Francia, se ha podido decir que "en materia de responsabilidad civil, los jueces del fondo tienen un poder soberano de apreciación en la fijación de los daños y

En tal sentido se pronuncia,entre otras, la sentencia de la Corte de París de 1 de diciembre 1992, Gaz.Pal. 1993, J.C.P. 1994, IV, pág. 201

Corte de Apelaciones de Santiago, 17 de diciembre de 1981, Rev. de Der. y Juris, t.78, secc.5, pág. 317 y 26 de septiembre de 1990, Gac. Jur. N¹23, pág.47; Corte de Apelaciones de San Miguel, 3 de junio de 1992, Rev, de Der. y Juris., T.89, sec. 4 , pág. 156 .

20 Esta es la doctrina constante del Tribunal Supremo. Por todas, sentencias de 25 de enero de 1968 (ref. $\left.n^{\circ} 523\right) ; 23$ de enero de 1970 (ref. $n^{\circ} 501$ ) y 29 de diciembre de 1993 (ref. $n^{\circ} 10.163$ ). 
perjuicios" ${ }^{21}$. Y en todos los sistemas, aún los más desarrollados, las críticas hacia la arbitrariedad son un lugar común.

Sin embargo, el reconocimiento de esa doctrina no supone ni ha de suponer una autorización para el abuso que repugna a la conciencia jurídica. De otro modo, resultarían ciertas las tesis que abogan por una limitación o incluso abrogación de esta categoría de daños ante los excesos a que ellas conducen, reclamo que alude a una serie de prácticas bastante frecuentes en los tribunales: conceder una indemnización por daño moral cuando no se han logrado probar los daños materiales, fijar una suma cuantiosa por este concepto cuando la indemnización por el daño material es reducida, fijar una suma cuantiosa cuando la conducta de responsable es especialmente reprochable, entre otras.

\subsection{1) HACIA UNA REVISIÓN DE LOS PRINCIPIOS QUE GOBIERNAN LA PRUEBA DEL DAÑO MORAL.}

El hecho efectivo que el daño moral no puede ser probado en los mismos términos que el daño material, no significa que por ello esté exento de prueba como equivocadamente lo ha sostenido nuestra jurisprudencia al resolver que "El daño moral por el carácter espiritual que reviste no debe ser fundamentado ni probado correspondiéndole al Juez apreciarlos prudencialmente de acuerdo al mérito del proceso y a las reglas de equidad" 22 o que "El daño moral es de indole netamente subjetiva y su fundamento se encuentra en la propia naturaleza afectiva del ser humano, de manera que puede decirse que tal daño se produce siempre por un hecho externo que afecta la integridad física y moral del individuo. Por lo tanto, la apreciación pecuniaria de ese daño debe considerarse por entero sometida a la estimación discrecional del juez, ya que dada su índole es inconcuso que no puede ni requiere ser acreditada" 23.

Sin embargo, en nuestra opinión, esa doctrina jurisprudencial requiere de una urgente revisión. En efecto, al igual que el daño material, el perjuicio moral también requiere ser acreditado puesto que la exigencia de prueba no es una que provenga de la naturaleza del perjuicio sino de principios probatorios procesales y sustantivos básicos. Todos los elementos necesarios para la procedencia de la acción de responsabilidad civil deben ser acreditados salvo que existan presunciones legales en tal sentido. Con mayor razón si nos centramos en aquel requisito que, como antes destacábamos, prácticamente constituye la base sobre la que se configura la responsabilidad. No cabe entonces introducir al respecto ninguna excepción en materia de daño moral so pena de transformarlo en un rubro indemnizatorio absolutamente arbitrario e incluso abusivo, que puede obtenerse con sólo invocarlo y que con ello se hace cuestionable. En efecto, una tesis como aquella desvirtúa la propia idea de indemnización pues, como ha sucedido en casos de nuestra realidad jurisprudencial, la pregunta que queda planteada es: ¿qué se está reparando?

\footnotetext{
21 Cass civ. 2, 20 de diciembre 1996: D.1967, pág. 669 y nota: Cass. Civ.1, 16 de julio de 1991: Bull.civ. nTM249, pág.164;

22 Corte de Apelaciones de San Miguel, 3 de junio de 1992, Rev. de Der. y Juris., t.89, secc.4, pág. 158.

23

Corte de Apelaciones de Santiago, 11 de octubre de 1984, Rev. de Der. y Juris., t.81, secc.2, pág, 121.
} 
Cuestión distinta es que, desde luego, ha de existir una mayor flexibilidad en su apreciación pero ello no significa que esta clase de perjuicios no deban ser acreditados. Celebramos algunas decisiones que ya se han pronunciado en tal sentido ${ }^{24}$.

Ahora bien, la prueba a rendir dependerá del tipo de perjuicio moral de que se trate, en otros términos en este aspecto cobra importancia el problema del concepto antes referido. Así, si consiste en la violación efectiva de un atributo de la persona, la prueba será relativamente sencilla en tanto la sola demostración de que se violó un atributo genera un daño. Si, en cambio, se refiere al dolor experimentado por la muerte de un ser querido, entonces habrá que acreditar la existencia efectiva del vínculo afectivo invocado lo que obliga, desde luego, a acreditar el parentesco, en su caso, pero ello no basta pues, contrariamente a lo sustentado por nuestra jurisprudencia, creemos que la sola condición de pariente no determina necesariamente la existencia del perjuicio.

Con ello aludimos a las verdaderas presunciones de Derecho de daño moral que nuestros tribunales han reiteradamente reconocido con ocasión del perjuicio infligido por la muerte o lesiones de la víctima a aquellas personas con las que se encontraba o encuentra ligada afectivamente y en las que ni siquiera exigen prueba del parentesco o vínculo afectivo invocado. Así, se ha reiteradamente sostenido que "aunque no haya prueba directa sobre el daño moral sufrido por el hermano de una persona asesinada, dedúcese de ese parentesco" 25 .

Cierto es que, normalmente esos atentados causados a personas con las que se tiene un vínculo estrecho de parentesco generan un perjuicio de afección que podría justificar una presunción pero que ha de permitir siempre la prueba en contrario pues, de no ser así, puede importar seria arbitrariedad, como ya ha sucedido entre nosotros ${ }^{26}$.

Por último, estos perjuicios pueden ser acreditados con todos los medios de prueba admitidos en nuestro sistema siendo particularmente relevantes a tal efecto los informes de peritos (médicos, en particular cuando se trata de dolor físico que puede ser acreditado, como ha sucedido en Europa con los daños corporales) y la prueba instrumental, si se intenta demostrar vínculo afectivo.

\subsection{2) HACIA UNA REVISIÓN DE LOS PRINCIPIOS QUE GOBIERNAN LA EVALUACIÓN DEL DAÑO MORAL.}

Ciertamente, como afirma Lambert-Faivre ${ }^{27}$, el problema que presenta la evaluación de los daños extrapatrimoniales o morales proviene del hecho, tan gráfico, de

24 Asi, C.Santiago, 8 de agosto de 1985, Rev. de Der. y Juris., t.82, secc.2, pág. 90 y C. Santiago, 8 de septiembre de 1992 comentada en la Revista de Derecho de la Universidad de Concepción POR DOMINGUEZ BENAVENTE Y DOMINGUEZ AGUILA, n¹94, págs, 159 y ss.

25.

Corte Suprema, 17 de enero 1985, Rev, de Der. y Juris., t.82, secc.4, pág.11.

26

Por todas, Corte Suprema, 15 de diciembre de 1983, Rev. de Der. y Juris., t.80, secc.1º, pág.128 citada y criticada por FUEYO, Instituciones de Derecho civil moderno, Santiago, 1990, pág.111 y por DOMINGUEZ AGUILA, Consideraciones en torno al daño. Una visión comparatista, en Revista de Derecho de la Universidad de Concepción, 1980, n²188, pág. 156 .

Lambert-Faivre, Droit du dommage corporel. Systemes d'indemnisation, Parıs, 1996, pág. 197 y 198. 
que, a diferencia de los daños materiales que se conjugan con el verbo tener en cuanto dicen relación con un derecho de tipo patrimonial, el atentado a la integridad física o psíquica de la persona se conjuga con el verbo ser, desde que dicen relación con la esencia misma de la persona de la víctima -cuerpo y alma- cuya relevancia, en nuestro caso, tiene jerarquía constitucional. Por lo mismo, la indemnización de estos perjuicios constituye la reparación satisfactoria del atentado a un derecho de la personalidad fundamental: la integridad del ser.

De aquí la dificultad que su apreciación presenta y que obliga, primero, a delimitar el daño moral del material, precisar sus conceptos, clarificar las especies de perjuicios, racionalizar la evaluación y normalizar su régimen jurídico.

Lo anterior permite explicar entonces porqué todos los esfuerzos han demostrado que, por su entidad y naturaleza, la objetivación deviene imposible pues estos perjuicios, sus secuelas y consecuencias, dependen de cada persona y de cada caso. Por ello es que, precisamente, en todos los sistemas se concede amplia facultad de apreciación a los tribunales de fondo, con los consiguientes resultados: variedad absoluta en el monto indemnizatorio, insuficiente fundamentación de la condena.

Sin embargo, alguna mayor certeza puede lograrse si, por una parte, se acogen algunos principios y, por otra, se abandonan ciertas prácticas que no hacen sino conducir a la arbitrariedad o a la inseguridad jurídica.

1) Abandono de las condenas genéricas por daño moral. Exigencia de una fundamentación judicial a la indemnización concedida.

Entre nosotros, como en general sucede en los demás sistemas pertenecientes a la familia de origen romano-germánico, existe una arraigada práctica jurisprudencial según la cuál los tribunales, al conceder una reparación a título de daño moral, simplemente se limitan a una condena en globo: señalan una suma genérica por ese concepto sin especificar ni cuáles son los criterios que se han considerado para evaluarlo en ese monto ni en qué ha consistido efectivamente el daño ordenado compensar.

A fin de evitar los peligros inherentes a tal solución, condenada muy fuertemente por la doctrina, en algunos sistemas se han dictado algunos textos legales que, de algún modo, fuercen a los tribunales a fundar sus resoluciones en esta materia indicando: en qué ha consistido el daño moral, porqué le cifra en determinada suma, cuáles han sido los criterios tenidos en cuenta para su valoración.

Así ha sucedido en Francia donde, aunque no existe un texto legal que de un modo general ordene esa precisión en las decisiones, ese ha sido el efecto indirecto de leyes como la de 5 de julio de 1985 cuyo art.31 distingue, a efectos de la acción de reembolso que tienen las entidades de la seguridad social contra el tercero responsable de un accidente causado a un asegurado social, entre los daños que dan lugar a prestaciones por parte de las entidades aseguradoras, del Estado o colectividades públicas cuyo reembolso estos tienen derecho a demandar (gastos médicos, farmacéuticos, de hospitalización, gastos de transporte, incapacidad temporal o permanente con consecuencias económicas) y aquellos daños llamados personales que corresponden exclusivamente a la víctima y respecto de los cuales no existe acción de reembolso: sufrimientos físicos y morales, pérdida del agrado de vivir y perjuicio estético. Lo mismo acontece en virtud de la ley de 6 de diciembre de 1976 que hace responsable al empleador. entre otros daños, por los sufrimientos físicos y morales, perjuicios estéticos y de agra- 
do, en caso de accidente laboral debido a una falta inexcusable de éste $\circ$ alguna de las personas que le han substituido en la dirección de la empresa.

Todo ello, contrariamente a lo que podría sostenerse, no ha de suponer una multiplicación del quantum indemnizatorio pues, por el contrario, obliga a un mayor esfuerzo probatorio, genera mayor transparencia y congruencia en el pronunciamiento y evita la doble indemnización de partidas que bien pudieran esconder un daño de idéntica naturaleza.

\section{2) Reconocimiento manifiesto del principio de reparación integral.}

La regla orientadora de toda indemnización debe ser el de la reparación integral del perjuicio esto es, la reparación no debe ser insuficiente ni excesiva. Claro está que, en el caso de los daños morales, debe tratarse de una "reparación razonable", en el sentido que la indemnización debe ser lo más integral posible. Decimos lo más integral posible porque ciertamente defender el principio de reparación integral en materia de daño moral equivale más o menos a no sostener nada, en el sentido de que un daño que por esencia resiste toda estimación nunca podrá ser completamente reparado. La idea de reparación sólo es válida con respecto a esta clase de daño, si la entendemos como una compensación $\mathrm{n}^{28}$ y no como el otorgamiento de una suma de dinero exactamente equivalente al daño, idea que, por lo demás, es incluso inapropiada respecto del daño material.

3) Progresiva precisión legislativa de los criterios de evaluación que deben ser considerados por el tribunal. Abandono de los factores punitivos.

No existe entre nosotros, ninguna claridad en cuanto a los criterios que deben ser considerados por el tribunal al momento de apreciar y evaluar el daño moral. Por el contrario, la variedad y multiplicidad de criterios empleados por nuestros tribunales es absoluta. Así, se ha resuelto por no citar sino algunas decisiones, que deben ser considerados diversos factores como son " a gravedad del hecho punible y el dolor que éste haya originado en la víctima ${ }^{29}$, "el grado y forma de participación de los demandados, la extensión de sus responsabilidades" 30 . "entidad, naturaleza y gravedad del suceso que causa el daño, la clase del derecho extrapatrimonial agredido, las consecuencias físicas, psíquicas, sociales o morales que derivan del daño causado, su duración y persistencia en el tiempo y la capacidad económica de las partes ${ }^{\prime 31}$. En un gran número de pronunciamientos, ni siquiera existe mención alguna a los factores que han sido considerados a la hora de fijar el quantum indemnizatorio.

De ello resulta, por un lado, que la determinación del monto de la reparación constituya un verdadero misterio que los litigantes deben descifrar o aún imaginar en cada proceso y ante cada decisión. Por otro, de aquellas decisiones que refieren sus consideraciones se infiere una clara confusión que quebranta de un modo manifiesto el

En tal sentido. muy acertadamente se pronuncia la sentencia de la Corte de Apelaciones de San Miguel de 2 de diciembre de 1988, Rev, de Der, y Juris. t.85, secc, 4, pág, 193

29

Corte de Apelaciones de Temuco, 9 de junio de 1987, Rev, de Der, y Juris., t.84, secc. 4, pág. 133.

30

Corte de Apelaciones de Santiago, 23 de octubre de 1991, Rev. de Der y Juris., t.88, secc.4, págs.159 y 160.

31

Corte de Apelaciones de Santiago, 4 de septiembre de 1991, Rev, de Der, y Juris., t.88, secc.4a, págs, 141 y 55. 
principio básico de la responsabilidad civil en conformidad al cual la medida de la suma de dinero que se concede a la víctima viene determinada única y exclusivamente por la entidad del perjuicio causado (todo el daño y nada más que el daño).

En efecto, son numerosos los criterios referidos por nuestros tribunales que reflejan que, en un gran número de ocasiones, la condena pecuniaria a título de daño moral no es exclusivamente reparadora sino claramente punitiva. No otra cosa resulta de la consideración a la capacidad económica de las partes o a la gravedad del hecho punible que ninguna función han de jugar en la responsabilidad civil, al menos mientras se siga defendiendo una concepción estrictamente resarcitoria.

De aquí que parezca pertinente exigir mayor precisión de los criterios emplea$\operatorname{dos}^{32}$. Así ha sucedido, en España donde sucesivos textos legales han ido acotando esa materia. Por ejemplo, en la Ley de Protección al honor, intimidad personal y familiar de 1982 "circunstancias del caso, gravedad de la lesión efectivamente producida, precisando que para este último parámetro ha de mirarse "a la difusión o audiencia del medio a través del que se haya producido o el beneficio obtenido por el causante de la lesión como consecuencia de la misma" ${ }^{33}$ y lo mismo sucede en la Ley de Propiedad Intelectual: "circunstancias de la infracción, gravedad de la lesión y grado de difusión ilicita de la obra" ${ }^{34}$. Así puede observarse también en México cuyo art.1916 inc. 4 del Código civil establece que : "El monto de la indemnización lo determinará el juez tomando en cuenta los derechos lesionados, el grado de responsabilidad, la situación económica del responsable, y la de la víctima, así como las demás circunstancias del caso" o en Argentina, cuyo art.522 del Código civil reformado, dispone que: "en los casos de indemnización por responsabilidad contractual el juez podrá condenar al responsable a la reparación del agravio moral que hubiere causado, de acuerdo con la indole del hecho generador de la responsabilidad y circunstancias del caso".

\section{4) Elaboración de baremos estadísticos.}

Ante la imposibilidad de fijar pautas objetivas para la evaluación de un daño como éste que escapa a toda objetividad, tal como lo han demostrado los detractores de la teoría del análisis económico -notablemente entre ellos ARLEN- y lo reconocen muchos de sus partidarios, los esfuerzos se han desplegado hacia idear soluciones que permitan, al menos, una cierta uniformidad en las decisiones judiciales. No debe olvi-

32 Un buen ejemplo de una adecuada precisión en un caso de accidente de tránsito que generó lesiones a la victima, el tribunal después de resaltar la dificultad que entraña el tratar de regular la cuantía el daño moral "en términos prudentes y justos" considera en tal operación "la naturaleza y gravedad de las lesiones médicamente comprobadas, la prolongada hospitalización de quince días, la intervención quirúrgica a que fue sometido, la incapacidad laboral de alrededor de mes y medio, el hecho de tratarse de un hombre casado de edad madura, el hecho de que no sólo haya debido sufrir los daños dejados en su cuerpo por el móvil embestidor, sino que ha debido soportar durante considerable tiempo la necesaria incertidumbre de su completa recuperación, concerniente ésta última nada menos que a su capacidad y habilidad motoras. Todo ello sin la más mínima negligencia de su parte". Corte de Apelaciones de Santiago, 28 de agosto de 1992. Gac.Jur. 146, pág. 72

33 Art. 9 inc. 3 de la Ley de 5 de mayo de 1982 de protección civil del derecho al honor, a la intimidad personal y familiar y a la propia imagen.

34

Art.125-2 de la Ley de Propiedad Intelectual de 11 de noviembre de 1987. 
darse que este es un aspecto de trascendental importancia respecto de la víctima, de las compañías de seguro y de los peritos médicos.

Para ello se han elaborado en prácticamente todos los países de la Comunidad Europea baremos orientadores de la reparación, elaborados generalmente por médicos expertos en daño corporal que intentan mostrar al juez los límites dentro de los cuáles debería moverse su evaluación.

Desde luego, no son baremos obligatorios para el tribunal pero si orientativos, puestos a su disposición para que se sitúe dentro de esos límites. De ese modo, se obtiene un progresivo acercamiento $y$, por lo mismo, uniformidad en el criterio de los distintos tribunales tanto respecto de las especies de daños susceptibles de ser reparados como del cálculo y del monto de las indemnizaciones que pretenden resarcirlos.

5) Publicación periódica de las indemnizaciones judiciales o transaccionales acordadas para cada rubro de daño no patrimonial.

Con la misma finalidad perseguida con la medida anterior, se han elaborado, en otros sistemas, publicaciones anuales donde se difunden el promedio de indemnizaciones acordadas por los tribunales o acordadas en transacciones para cada especie de daño extrapatrimonial. Se trata de publicaciones controladas por la autoridad pública, remitidas a todos los tribunales, cuyo financiamiento se ha entregado a las Compañías de Seguros - en atención a la utilidad que ellos obtienen de la certeza en el riesgo- y que dan cuenta de estadísticas elaboradas en base a variados parámetros: edad de la vícti$\mathrm{ma}, \mathrm{sexo}^{35}$, actividad que realizaba, entre otros.

Con esta medida se consigue obtener una estadística que permita a los tribunales uniformar sus decisiones y, con ello, conceder un tratamiento igualitario de las víctimas, muy especialmente de las que han sufrido daño corporal.

6) Uniformación de la fecha o el momento en que se sitúa el juez al momento de efectuar la evaluación.

Como es sabido, la variedad de criterios jurisprudenciales en cuánto a cuál es la fecha o el momento en que debe situarse el juez al momento de efectuar la evaluación es absoluta,

Una medida evidente de corrección en aras de la seguridad está constituida por la uniformación en el criterio ya sea que se opte por mirar a la época del accidente o del hecho generador del daño, criterio teóricamente más correcto, ya sea el de la fecha de la sentencia pues ambos plantean problemas prácticos e incluso de equidad ${ }^{36}$.

Aspecto importante, por ejemplo, cuando se trata de daño estético pues no es lo mismo dejar deforme a un hombre que a una mujer, a tina mujer casada que a una soltera. En Francia, las estadísticas han revelado que aunque la esperanza de vida de las mujeres es superior a la de los hombres, la indemnización que se fija por la pérdida del agrado de vivir es menor.

Así, la fecha del hecho ilicito plantea el problema de cómo considerar el tiempo que va entre esa fecha y aquella en que efectivamente se fija la indemnización. A la inversa, el de la fecha de la sentencia tiene el defecto contrario. 


\section{4) EL RESARCIMIENTO DEL DAÑO MORAL DERIVADO DE CONTRATO.}

Uno de los aspectos más discutidos en nuestro Derecho en materia de responsabilidad civil es el relativo a la procedencia de una indemnización por el daño moral derivado de contrato. Precisamente, una de las clásicas diferencias reseñadas entre el estatuto de la responsabilidad civil extracontractual y contractual se hace consistir en la amplia procedencia de una reparación por daño moral en la primera frente a un nítido rechazo a su admisibilidad en la segunda. Esta distinción, pese a su reiterada invocación, requiere, sin lugar dudas, de una urgente revisión y adaptación.

Como se habrá advertido nos referimos a "daño moral derivado de contrato" y no "daño moral contractual" pues, uno de los principales aspectos que determina la dicotomía que en esta materia se produce en Chile, proviene de la terminología comúnmente empleada para referirse a la especie de perjuicio en estudio cuando se produce en el ámbito contractual. En efecto, la expresión recurrente entre nosotros es la de "daño moral contractual" que, en nuestra opinión, no hace sino generar confusión desde que conduce a pensar que en ese caso el perjuicio es distinto al extracontractual. Ello constituye un profundo error pues, en ambas situaciones, la naturaleza o la esencia del daño moral es la misma, ya sea que se cause por la violación de una obligación nacida de un contrato o del deber general de respeto a los demás, más conocido como naeminem laedere. En otros términos, en ambos ámbitos de la responsabilidad el concepto del daño en cuestión es el mismo y la diferencia que existe entre ellos sólo está en que, en un caso, proviene de la infracción del contrato y, en el otro, proviene del hecho ilícito. En atención a ello es que parece más pertinente referirse al "daño moral derivado de contrato", expresión más comprensiva de lo que venimos de resaltar.

Bien sabemos, que el rechazo a una indemnización del daño moral derivado de contrato encuentra su fundamento en nuestro pais en una interpretación excesivamente exegética de nuestra jurisprudencia que se enfrenta a la tendencia más avanzada de plena resarcibilidad del perjuicio no patrimonial sin distinción. Cierto es, no obstante, que si nosotros revisamos el Derecho Comparado no podemos encontrar una opinión unánime al respecto. Por el contrario, las soluciones son diversas dependiendo de la familia o, dentro de ella, del sistema jurídico en el que nos situemos ${ }^{37}$.

Así, en el Common Law, se ha llegado después de un largo camino, a acoger el denominado non economic loss en el ámbito de los contracts. En el seno de la familia de origen romano-germánico, en cambio, las soluciones son muy diversas en términos tales que podemos encontrar desde sistemas reacios a su resarcimiento donde, curiosamente, encontramos como único exponente al Derecho chileno o sistemas intermedios en los que, pese a haberse admitido la reparación del daño moral derivado de contrato, todavía no existe una completa uniformación de todos los principios que regulan al perjuicio extrapatrimonial, tales como España. Finalmente, se destacan aquellos sistemas donde el resarcimiento de la clase de perjuicio en estudio en materia contractual no reconoce diferencia alguna con el producido en el ámbito extracontractual como sucede, muy señaladamente, en el Derecho francés. Tanto es así que una simple revisión de cualquier obra general de Derecho civil en la materia permite constatar que

Véase con más detalle al respecto nuestro artículo " $L a$ indemnización del daño moral. " antes citado. 
el problema de la procedencia del daño moral derivado de contrato ni siquiera se refiere pues toda la doctrina relativa al perjuicio en análisis se entiende común a toda la responsabilidad civil. Existe pues, una absoluta unidad de regulación alcanzada-conviene resaltarlo- por vía jurisprudencial sin que haya sido necesario introducir reforma alguna al Code. Se distingue asi, por tanto, de otros Derechos como el argentino o mexicano que, después de reformas introducidas a sus Códigos civiles, contienen normas que expresamente ordenan al tribunal indemnizar el daño moral proveniente del incumplimiento contractual.

Con todo, aunque la diversidad de soluciones es manifiesta conviene resaltar que no ha existido nunca ni existe en el presente un texto legal que prohiba la reparación del daño moral en el ámbito contractual. En tal sentido, en aquellos sistemas donde ha existido reticencia ella ha provenido o proviene más bien de interpretaciones efectuadas por la jurisprudencia, en especial, el rechazo a acoger un principio de resarcimiento está más bien en una lectura restrictiva de las normas resarcitorias contenidas en los códigos. Así, sucede, desde luego, entre nosotros pero además en sistemas como el alemán o italiano donde existe, en general, una concepción restrictiva de la indemnización por daño no patrimonial.

Los obstáculos opuestos a la indemnización del perjuicio extrapatrimonial en el campo contractual son variados. Asi, un primer gran impedimento se ha centrado en la pretendida exigencia de patrimonialidad de la prestación contenida en toda obligación. Como se ha defendido, si toda prestación ha de tener un contenido económico, la reparación del daño moral deviene imposible pues, por un lado, resulta inconcebible una obligación con contenido extrapatrimonial cuyo cumplimiento forzado quedaría excluido y, por otro, aún admitiendo esa posibilidad, su infracción no podría generar el deber de resarcir. Conviene resaltar que este debate álgido en Derechos como el italiano o en el español, no ha sido relevante en Chile pues la fundamentación del rechazo se ha centrado en otro aspecto. Por lo demás, en nuestra opinión, introducirnos en ese debate sólo supondría importar una discusión que no se justifica en nuestro sistema. En efecto, a diferencia de lo que acontece en el Derecho italiano donde la polémica encuentra su origen en la expresa exigencia del Codice de patrimonialidad en la prestación, nuestro Código civil no contiene ninguna limitación en tal sentido, de suerte que, no existe impedimento legal que fuerce a excluir a las obligaciones no patrimoniales de la idea misma de obligatio.

En nuestro sistema, el rechazo a conceder una indemnización por el daño moral derivado de contrato ha encontrado su fundamento en una lectura restrictiva de las normas resarcitorias, en particular, del art.1556 del Código civil en conformidad a la cual, dado que el referido precepto sólo ordena indemnizar el daño emergente y el lucro cesante, forzoso es entender que, con ello, el legislador quiso excluir al perjuicio moral.

Ciertamente no debe pensarse que esta constituya una argumentación propia de nuestro sistema pues no es sino la repetición de una clásica, sustentada en un primer tiempo en Francia y, luego, reproducida en todos los Derechos cuyas codificaciones se inspiraron en el Código de Napoléon. En efecto, tan pronto se plantee en Francia el debate en torno a la partida resarcitoria en estudio la primera objeción se hará consistir. precisamente, en los términos empleados por el legislador en el art.1149 del Código civil (equivalente a nuestro art.1556) y se dirá entonces que los conceptos "pérdida" y "ganancia" utilizados son de contenido estrictamente material, dejando fuera al perjui- 
cio moral. Esa afirmación se entenderá sustentada ya desde el Derecho romano que, siguiendo, las opiniones de DOMAT rechazaba la indemnización del daño moral en el ámbito contractual. No debemos olvidar que, por expresa indicación de los redactores del Código de Napoleón, todo vacío contenido en ese cuerpo legal debía ser completado a la luz de las enseñanzas romanas. De aquí que, cuando los primeros comentaristas intenten resolver el problema en análisis, opten por remitirse a la fuente ya referida $y$, ante la ausencia de pronunciamiento fijo al respecto, recurran a la obra de DOMAT. Más tarde, un estudio más detenido de la cuestión revelará que la opinión sustentada por este célebre autor sólo correspondía al Derecho romano de la primera época pues, en el Bajo Imperio, diversos antecedentes permiten demostrar la existencia de un principio de resarcibilidad del daño moral derivado de contrato. DOMAT habría errado en su conclusión simplemente porque esos antecedentes nunca llegaron a su conocimiento.

Advertido el error, rápidamente se reinterpretará el art.1149 del Código civil abriendo las puertas al daño moral sobre la base que los términos "pérdida" y "ganancia" son amplios; permitiendo claramente su inclusión. Y esta nueva interpretación pasará posteriormente a todos los Derechos inspirados en ese cuerpo legal aunque, curiosamente, con la notable excepción del Derecho chileno que, hasta el presente, sigue anclado en la vieja doctrina.

Algunas señales de cambio pueden, sin embargo, advertirse recientemente. La más importante se encuentra en la sentencia de 20 de octubre de $1994^{38}$ donde nuestra jurisprudencia, por primera vez, ha asentado el principio de la plena resarcibilidad del daño no patrimonial producido por el incumplimiento de una obligación contractual. Esta decisión tiene el mérito de volver sobre la clásica lectura del art. 1556, al resolver que la referida disposición al no pronunciarse expresamente sobre la procedencia del daño moral no permite excluirlo sin más. $Y$ todo ello reforzado por una novedosa interpretación de las normas resarcitorias contenidas en el Código civil desde la Constitución. Decimos novedosa porque aunque la interpretación del ordenamiento inferior a la luz de la Constitución es un elemento de hermenéutica más que admitido en sistemas como el español o italiano, su recepción no ha llegado aún al nuestro.

Todo lo anterior permite anticipar 0 , por lo menos esperar, una evolución de nuestro Derecho en la materia que, por un lado, no haría sino adaptarlo a los principios más modernos imperantes en el Derecho comparado y, por otro, $y$, en lo que es más importante, constituye un imperativo emanado de la simple lógica y de toda equidad al no existir fundamentos que autoricen a introducir una distinción tan radical en el seno de la responsabilidad civil.

Sin perjuicio de lo recién referido, habrá que tener presente que la sola admisión de una reparación del daño moral derivado de contrato no despeja a esta partida resarcitoria de su natural complejidad proveniente de la conjunción que plantea de dos delimitaciones -daño moral e incumplimiento contractual- que son de suya difíciles de hacer. En tal sentido, su reparación obliga a exigir, por un lado, que se trate efectivamente de un perjuicio no patrimonial, en el sentido que no todo incumplimiento contractual genera un daño moral pues las molestias y desagrados son propios de toda infracción de la obligación convenida. En otros términos, a todo acreedor le perturba y 
afecta no obtener la prestación prometida pero esa sola perturbación no puede estimarse como daño no patrimonial sino cuando ha alcanzado la entidad e importancia de esa categoría de perjuicio, juicio que depende, como es evidente, del concepto admitido en el respectivo sistema.

Por otra parte, debe tratarse de un daño moral "derivado de contrato", esto es generado directamente por la infracción de un contrato, lo que fuerza a acotar el campo de lo contractual, forzando a una de las labores más arduas planteadas por la responsabilidad civil al no existir pautas exactas de delimitación. $Y$ si en otros sistemas más adelantados en la materia como el español o el francés, se han realizado notorios esfuerzos por precisar qué es lo contractual advirtiéndose finalmente que esa precisión sólo es posible por el recurso a la facultad de integración de todo contrato consagrada en todos los Códigos decimonónicos, en nuestro Derecho ese tipo de análisis y evolución no se ha producido. Entre nuestro país, el art.1546 del Código civil constituye todavía una norma de aplicación reducida sin que se haya advertido la riqueza y utilidad que tiene en orden a precisar aspectos tan importantes en materia de daño moral derivado de contrato como la naturaleza del contrato y el ámbito de lo previsible, esto es de los daños que debe entenderse que entraron dentro del cálculo de riesgos del acreedor.

Es de esperar, finalmente, que la evolución que venimos de reseñar llegue también a nuestro país aunque entre límites que rindan adecuado homenaje tanto a la justicia como al afán de tutela de la persona. 